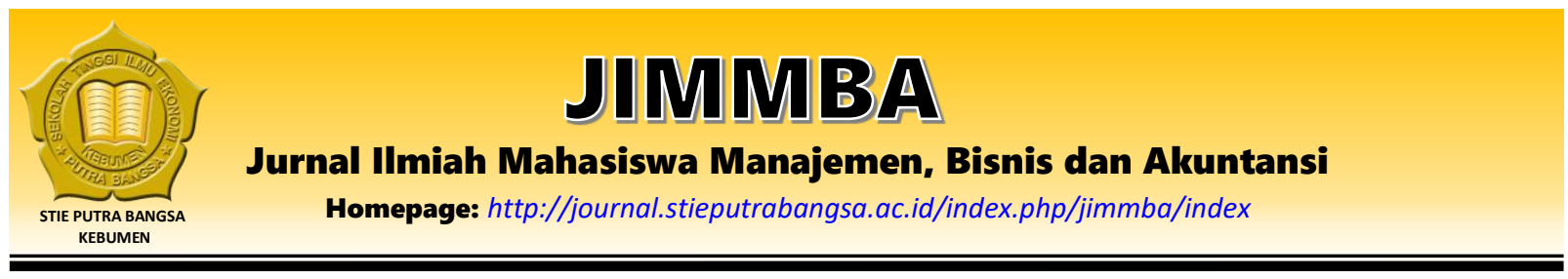

\title{
Pengaruh Word of Mouth, Healthy Lifestyle, dan Brand Image Terhadap Keputusan Pembelian Sepeda Merek Polygon di Kabupaten Kebumen
}

\author{
Agung Triyono ${ }^{1}$, Dewi Noor Susanti ${ }^{2}$ \\ 1,2 Universitas Putra Bangsa \\ agungtriyono413@gmail.com ${ }^{1}$
}

\section{ARTICLE INFO}

Article History:

Received: June 30th 2021

Accepted: July 31 2021

Published: August 9th 2021

Keywords:

Word of Mouth, Healthy

Lifestyle, Brand Image,

Purchasing Decisions

\begin{abstract}
This study aims to examine and analyze the influence of word of mouth, helathy lifestyle and Brand Image on purchasing decisions. This research was conducted in the community of Kebumen Regency. Data collection was carried out by distributing questionnaires to 100 respondents who use the Polygon bicycle brand, Kebumen Regency. The technique of collecting data by distributing questionnaires. The analysis used is the validity test, reliability test, classic assumption test, multiple linear regression analysis test and the coefficient of determination. The analysis technique used is using the analysis program SPSS Version 25 for Windows. The results obtained in this study indicate that the variables word of mouth, healthy lifestyle and Brand Image have a significant effect on purchasing decisions. The word of mouth variable has a significant effect on purchasing decisions, the helathy lifestyle variable has a positive and significant effect on purchasing decisions, while the Brand Image variable has a insignificant effect on purchasing decisions.
\end{abstract}

\section{Pendahuluan}

Dunia saat ini sedang mengalami kondisi pandemi Covid-19, termasuk juga di dalamnya negara Indonesia. Indonesia juga menjadi salah satu negara yang mempunyai jumlah pasien covid-19 yang cukup tinggi, itu mengakibatkan banyak hal yang harus di lakukan demi menjaga kelangsungan hidup semua masyarakat. Dalam situasi pandemi Covid-19 saat ini, masyarakat dituntut untuk menjaga pola hidup sehat, berbagia carapun dilakukan oleh masyarakat untuk menjaga kesehatan mereka. Banyak hal yang dapat dilalukan oleh masyarakat saat pandemi seperti ini, seperti menjaga jarak, selalu cuci tangan, di larang berkerumuan dan rajin berolahraga. Hal yang saat ini yang sedang trend dalam menjaga kesehatan yaitu berolahraga sepeda. Saat ini, olahraga bersepeda menjadi salah satu pilihan untuk jadi tahes (sehat) di masa pandemi Covid-19. Bersepeda dipilih karena selain praktis dan mudah dilakukan, namun juga masyarakat masih bisa tetap tampil trendi dalam berolahraga.

Perkembangan dunia bisnis pada era globalisasi ini semakin hari semakin berkembang, hal ini dapat ditandai dengan adanya persaingan antar perusahaan satu dengan perusahaan lainnya untuk menarik perhatian konsumen. Keadaan seperti ini membuat perusahaan 
harus merencanakan strategi pemasaran yang efektif, yang bertujuan untuk mempertahankan kelangsungan hidup perusahaan serta untuk mengembangkan perusahaan. Salah satu kelompok perusahaan yang saat ini sedang berkembang adalah perusahaan kendaraan, khususnya produk sepeda.

Polygon Bikes adalah salah satu perusahaan yang memproduksi sepeda. Berdiri pada tahun 1989, Polygon Bikes memiliki visi untuk menjadi merek sepeda yang berkualitas global dan siap bersaing di pasar internasional. Berawal dari sebuah perusahaan kecil yang berorientasi untuk memproduksi sepeda khusus untuk ekspor, 10 tahun pertama adalah proses pembelajaran dan fokus Polygon untuk persiapan pengembangan brand secara mandiri. Mulai tahun 2000, Polygon mulai melakukan ekspansi perluasan pabrik dan investasi ke alat berteknologi tinggi standar internasional. Polygon memiliki pabrik, perakitan, dan jaringan pendistribusian mandiri yang telah memenuhi standar dunia sehingga dapat terus mengontrol setiap aspek mulai dari ide awal hingga ke pengiriman akhir sepeda dengan kualitas tinggi. Memiliki visi untuk menjadi brand global yang terus mengedepankan otentisitas, originalitas dan kualitas, hingga kini Polygon Bikes telah terdistribusi di 500 outlet yang tersebar di berbagai belahan dunia, dan terdistribusi sampai dengan 33 negara.

Dengan menyediakan berbagai macam jenis sepeda, produk polygon mempunyai produk dengan kualitas bagus yang di kenal masyarakat Indonesia. Untuk kategori produk sepeda menurut survey TOP brand Polygon dan kompetitior lainnya pada tahun 2018 dan 2019 terlihat pada tabel berikut ini:

Tabel 1. Top Brand Sepeda 2018 dan 2019

\begin{tabular}{cllll}
\hline No & \multicolumn{1}{c}{ Brand } & TBI 2018 & \multicolumn{1}{c}{ TBI 2019 } & Ket \\
\hline 1 & Polygon & $40.0 \%$ & $22.0 \%$ & TOP \\
2 & Wim Cycle & $12.8 \%$ & $16.2 \%$ & TOP \\
3 & Phoenix & $12.2 \%$ & $15.3 \%$ & TOP \\
4 & United & $8.8 \%$ & $9.7 \%$ & \\
5 & Mustang & $4.8 \%$ & $10.2 \%$ & \\
Sumber: topbrandeaward.com & & &
\end{tabular}

Berdasarkan tabel TOP Brand di atas menunjukukan bahwa produk sepeda merek Polygon di tahun 2018 dan 2019 selalu menempati posisi pertama dibandingan merek sepeda lainnya. Itu membuktikan bahwa sepeda merek Polygon di Indonesia menjadi pilihan utama bagi masyarakat.

Dalam menentukan variabel untuk penelitian yang akan dilakukan oleh penulis, maka penulis melakukan observasi terlebih dahulu yang di lakukan teradap 30 responden pengguna sepeda merek Polygon di Kabupaten Kebumen. Berikut hasil observasi yang di lakukan oleh penulis.

Tabel 2. Data Observasi pada Pengguna Sepeda Merek Polygon di Kabupaten Kebumen

\begin{tabular}{llll}
\hline No & Faktor yang Mempengaruhi & Jumlah Responden & Persentase \\
\hline 1 & Word Of Mouth & 11 & $37 \%$ \\
2 & Brand Image & 5 & $17 \%$ \\
3 & Healthy Lifestyle & 9 & $30 \%$ \\
4 & Price & 3 & $10 \%$ \\
5 & Quality Product & 2 & $7 \%$ \\
\hline & Total & 30 & $100 \%$
\end{tabular}

Sumber: Data primer diolah tahun 2021 
Berdasarkan hasil observasi yang dilakukan peneliti pengguna sepeda merek Polyogon di Kabupaten Kebumen dipengaruhi beberapa faktor yaitu Word Of Mouth, Brand Image, Healthy Lifestyle, price dan quality Prodict. Hasil dari observasi awal yaitu Word Of Mouth, Brand Image, Healthy Lifestyle mendapatkan 3 hasil teratas yaitu Word Of Mouth mendapatkan 11 responden atau 37\%, Healty Lifestyle mendapatkan 9 responden atau 30\% dan Brand Image mendapatkan 5 responden atau $17 \%$.

Sebagian besar proses komunikasi antar manusia dilakukan melalui berkomunikasi dengan orang lain. Komunikasi tersebut dilakukan secara komunikasi lisan dengan orang lain karena setiap harinya seseorang berbicara,bertukar fikiran, bertukar informasi, saling memberikan pendapat. Proses komunikasi tersebut merupakan sifat dari manusia yang ingin bersosialisasi dengan orang lain. Word Of Mouth Communication atau komunikasi lisan tergantung pada penyebaran informasi yang dilakukan seseorang kepada orang lain. Solomon (2013) menyebutkan bahwa Word Of Mouth merupakan informasi tentang produk yang disalurkan oleh individu ke individu lain. Komunikasi yang baik dan optimal bergantung pada peran komunikator. Komunikator pada Word Of Mouth ialah individu yang sudah pernah memiliki dan menggunakan sehingga mempunyai pengalaman akan suatu produk.

Menurut Sutisna (2010) lifestyle (gaya hidup) dapat diidentifikasikan bagaimana pola kehidupan seseorang dalam menghabiskan waktunya (aktivitas), minat (ketertarikan) dan perilakunya pada kegiatan sehari-hari (pendapat). Menurut Mister (2008) gaya hidup sehat adalah cara menyelenggrakan proses kehidupan sehingga memberikan kondisi positif bagi diri sendiri dan lingkungan. Persepsi gaya hidup antara satu individu dengan individu yang lain berbeda dalam membentuk citra dari lingkungan sekitarnya.

Menurut Kotler dan Keller (2012:241), brand atau merek adalah suatu nama, istilah, tanda, simbol, desain atau kombinasi dari semuanya yang dimaksudkan untuk mengidentifikasikan suatu barang atau jasa dari suatu penjual atau sekelompok penjual dan untuk membedakannya dari kompetitor lain. Menurut Tjiptono (2011:112), citra merek atau Brand Image yakni deskripsi tentang asosiasi dan keyakinan konsumen terhadap merek tertentu. Citra merek adalah bagaimana persepsi konsumen menganggap atau menilai (merek) suatu perusahaan secara actual, seperti tercermin dalam asosiasi yang terjadi dalam memori konsumen (Kotler dan Keller, 2012:332).

\section{Kajian Teori dan Telaah Literatur}

\section{Keputusan Pembelian}

Menurut Kotler dan Keller (2012:190), keputusan pembelian adalah tahap dalam proses pengambilan keputusan dimana konsumen benar-benar membeli. Menurut Kotler dan Keller (2008) indikator keputusan pembelian yaitu:

1. Kebutuhan

2. Publik

3. Manfaat

4. Sikap orang lain

5. Kepuasan 


\section{Word of Mouth}

Menurut Hasan (2010:230) Word Of Mouth merupakan bagian dari stretagi promosi dalam kegiatan pemasaran yang menggunakan "orang ke orang" yang puas untuk meningkatkan kesadaran produk dan menghasilkan tingkat penjualan tertentu. Komunikasi dari mulut ke mulut menyebar melalui jaringan bisnis, sosial dan masyarakat yang di anggap sangat berpengaruh. Menurut Babin, Barry (2014:133) indikator Word of Mouth :

1. Kemauan konsumen dalam membicarakan hal-hal positif tentang kualitas, pelayanan, dan produk kepada orang lain.

2. Rekomendasi jasa dan produk perusahaan kepada orang.

3. Dorongan terhadap teman atau relasi untuk melakukan pembelian terhadap produk dan jasa perusahaan.

\section{Healthy Lifestyle}

Menurut Mister (2008) gaya hidup sehat adalah cara menyelenggrakan proses kehidupan sehingga memberikan kondisi positif bagi diri sendiri dan lingkungan. Gaya hidiup adalah fungsi motivasi konsumen dan pembelajaran sebelumnya. Menurut Josep Plumer (dalam Suryani, 2008) indikator healthy lifestyle yaitu sebagai berikut :
1. Aktivities (kegiatan)
2. Interest (minat)
3. Opinion (opini)

\section{Brand Image}

Menurut Kotler dan Keller (2012:241), brand atau merek adalah suatu nama, istilah, tanda, simbol, desain, atau kombinasi dari semuanya yang dimaksudkan untuk mengidentifikasikan suatu barang atau jasa dari satu penjual atau sekelompok penjual dan untuk membedakannya dari kompetitor lain. Menurut Lamb et all dalam Aprianto (2016), indikator Brand Image yaitu sebagai berikut:

1. Merek mudah diingat

2. Kualitas keseluruhan produk

3. Keterkenalan produk

4. Merek terpercaya

\section{Model Penelitian}

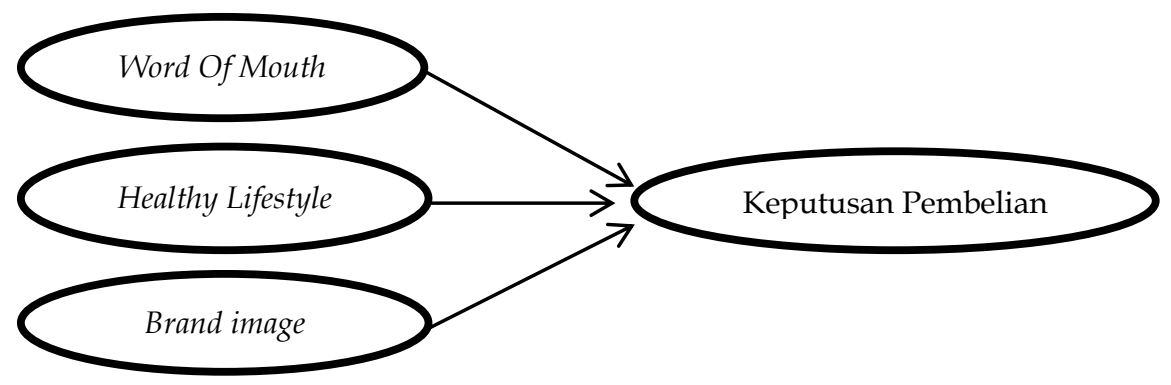

Gambar 1. Model Penelitian 


\section{Metode Penelitian}

\section{Uji Validitas}

Uji validitas dilakukan semua intrumen variabe penelitian yaitu variabel bebas (independen) Word Of Mouth, Healthy Lifestyle, Brand Image dan variabel terikat (dependen) Keputusan Pembelian. Kuesioner dinyatakan valid apabila korelasi ( $\mathrm{r}$ hitung) $>$ ( $\mathrm{r}$ tabel) dengan tingkat signifikan < 0,05 maka diperoleh ( $\mathrm{r}$ tabel) 0,1966 dari 100 responden.

\section{Uji Reliabilitas}

Menurut Ghozali (2011), uji relibilitas adalah alat ukur untuk mengukur suatu kuesioner yang merupakan indikator dari variabel atau konstruk. Suatu kuesioner dikatakan reliabel atau handal jika jawaban seseorang terhadap pernyataan adalah konsisten atau stabil dari waktu ke waktu. Berdasarkan hasil uji reabilitas menunjukan bahwa nilai cronbach alpha untuk variabel Word Of Mouth 0,861 untuk variabel Healthy Lifestyle 0.659, Brand Image 0.854 dan variabel Keputusan Pembelian 0.694. Berdasarkan dari hasil perhiungan tersebut, dapat dinyatakan bahwa seluruh pernyataan pada semua variabel penelitian dinyatakan reliabel karena nilai cronbach alpha nya diatas 0,60 .

\section{Uji Asumsi Klasik}

\section{Uji Multikonieritas}

Uji Multikorelasi bertujuan untuk mengetahui apakah hubungan diantara variabel bebas memiliki masalah multikorelasi (gejala multikolinearitas) atau tidak. Multikorelasi adalah korelasi yang sangat tinggi atau sangat rendah yang terjadi pada hubungan diatara variabel bebas. Multikorelasi dapat dilihat dari nilai VIF (variance-inflating factor) kurang dari 10.

Tabel 3. Hasil Uji Multikonieritas

\begin{tabular}{ccc}
\hline \multirow{2}{*}{ Model } & \multicolumn{2}{c}{ Collinearity Statistic } \\
\cline { 2 - 3 } 1. (constant) & Tolerance & VIF \\
Word Of Mouth & 0,669 & 1,495 \\
Healthy Lifestyle & 0,805 & 1,243 \\
Brand Image & 0,663 & 1,581 \\
\hline
\end{tabular}

Sumber : data primer diolah, tahun 2021

Berdasarkan tabel diatas, dapat diketahui bahwa semua variabel independen memiliki VIF kurang dari 10 dan nilai tolelance lebih besar dari 0,1. Dari data yang ini dapat diartikan bahwa tidak terjadi gejala multikonieritas antar variabel bebas, sehingga model dapat dipakai. 


\section{Uji heterokedastisitas}

Heterokedatisitas menunjukan bahwa varians tabel tidak sama untuk semua pengamatan/observasi Uji heteroskedastisitas mendasarkan pada distribusi residu (selisih hasil observasi dan model regresi linear berganda) guna mengetahui adanya gejala heteroskedastisitas atau tidak.

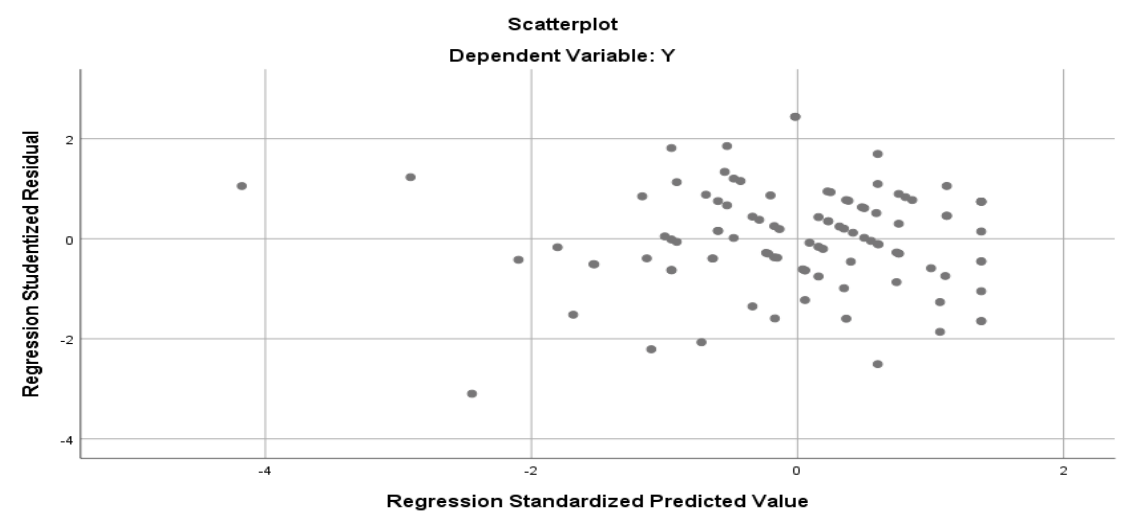

Gambar 2. Hasil Uji Heterokedastisitas

Sumber : data primer diolah, tahun 2021

Berdasarkan gambar diatas menunjukkan bahwa tidak ada pola tertentu, seperti titik-titik yang membentuk pola tertentu yang teratur (bergelombang, melebar, kemudian menyempit) dan tidak ada pola yang jelas sehingga dapat disimpulkan model regresi tidak terjadi heteroskedastisitas.

\section{Uji Normalitas}

Uji normalitas bertujuan untuk mengetahui normal atau tidaknya suatu distribusi data. Pada dasarnya uji normalitas adalah membandingkan antara data yang kita miliki dan data berdistribusi normal yang memiliki mean dan standar deviasi yang sama dengan data. Analisis statistik untuk menguji normalitas dilakukan dengan uji kolmogornov smirnov yang mensyaratkan nilai Test Statistic adalah tidak signifikan yaitu $>0,05$. Hasil uji normalitas pada penelitian ini dapat di lihat pada tabel berikut:

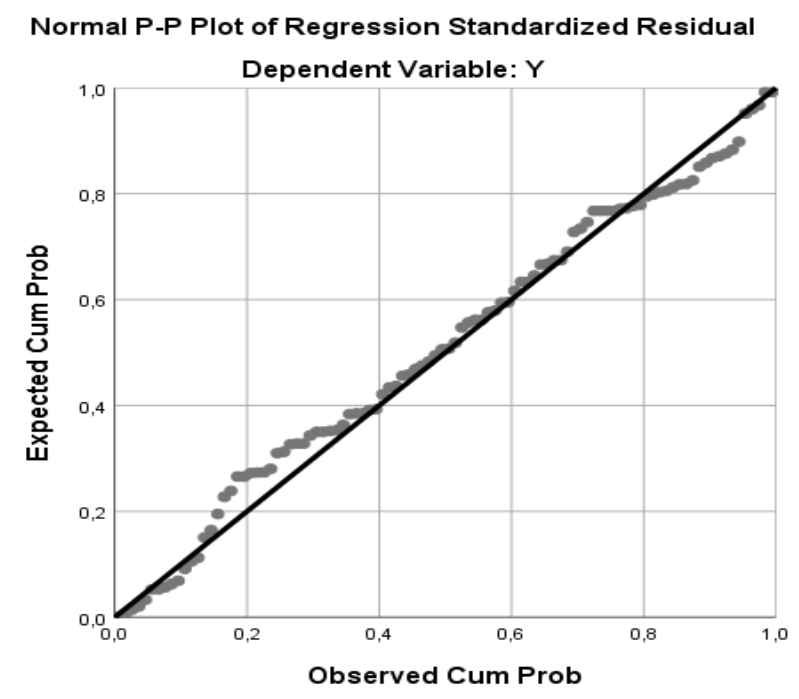

Gambar 3. Hasil Uji Normalitas

Sumber: Data primer diolah, tahun 2021 
Berdasarkan gambar 3 (Normal P-P Plot of Regression Standardized Residual) diketahui bahwa data menyebar di sekitar garis diagonal dan mengikuti arah garis diagonal, maka model regresi tersebut memenuhi asumsi normalitas.

\section{Uji Analisis Linear Berganda}

Tabel 4. Uji Analisis Linear Berganda

\begin{tabular}{ccccccc}
\hline \multirow{2}{*}{ Model } & \multicolumn{2}{c}{$\begin{array}{c}\text { Unstandardized } \\
\text { Coefficients }\end{array}$} & $\begin{array}{c}\text { Standardized } \\
\text { Coefficients }\end{array}$ & \multirow{2}{*}{ T } & \multirow{2}{*}{ Sig. } \\
\cline { 2 - 4 } & B & Std. Error & Beta & & \\
\hline \multirow{4}{*}{1} & 2,668 & 1,340 & & 1,991 &, 049 \\
& (Constant) &, 527 &, 101 &, 413 & 5,212 &, 000 \\
WOM &, 631 &, 102 &, 447 & 6,176 &, 000 \\
& HEALTHY LIFESTYLE &, 137 &, 112 &, 100 & 1,231 &, 221 \\
\hline
\end{tabular}

Sumber : data primer diolah, tahun 2021

Model hubungan variabel-variabel tersebut menurut Ghozali (2005) dapat disusun dalam fungsi atau persamaan sebagai berikut :

$$
\begin{aligned}
& Y=a+b 1 X 1+b 2 X 2+b 3 X 3+e \\
& Y=2,668+0,527 X_{1}+0,631 X_{2}+0,137 X_{3}
\end{aligned}
$$

\section{Uji $\mathbf{t}$}

\section{Word of Mouth}

Hasil uji $t$ pada tabel IV-18 variabel word of mouth nilai $t$ hitung sebesar 5,212 $>\mathrm{t}$ tabel 1,985 dengan tingkat signifikasi sebesar 0,000 < 0,05, maka dapat disimpulkan bahwa variabel word of mouth memiliki pengaruh signifikan terhadap keputusan pembelian dan $\mathrm{H}_{0}$ ditolak dan $\mathrm{H}_{1}$ diterima.

\section{Healthy Lifestyle}

Hasil uji $\mathrm{t}$ pada tabel IV-18 variabel healthy lifestyle nilai $\mathrm{t}$ hitung sebesar 6,176 $>\mathrm{t}$ tabel 1,985 dengan tingkat signifikasi sebesar 0,000 <0,05, maka dapat disimpulkan bahwa variabel healthy lifestyle memiliki pengaruh signifikan terhadap keputusan pembelian dan $\mathrm{H}_{0}$ ditolak dan $\mathrm{H}_{2}$ diterima.

\section{Brand Image}

Hasil uji $\mathrm{t}$ pada tabel IV-18 variabel Brand Image nilai $\mathrm{t}$ hitung sebesar 1,231 $<\mathrm{t}_{\text {tabel }} 1,985$ dengan tingkat signifikasi sebesar 0,221 >0,05, maka dapat disimpulkan bahwa variabel Brand Image tidak memiliki pengaruh yang signifikan terhadap keputusan pembelian dan $\mathrm{H}_{0}$ diterima dan $\mathrm{H}_{3}$ ditolak.

\section{Uji F}

Hasil perhitungan dengan menggunakan SPSS diperoleh $\mathrm{F}$ hitung sebesar 47,170 dengan tingkat signifikasi $0,000<0,05$ dan nilai $\mathrm{F}_{\text {hitung }}>\mathrm{F}$ tabel $(47,170>2,70)$. Konsekuensinya adalah Ho ditolak dan Ha diterima. Dengan demikian terbukti bahwa ada pengaruh yang signifikan dari word of mouth, healthy lifestyle dan Brand Image secara bersama-sama berpengaruh signifikan terhadap keputusan pembelian.

\section{Uji Determinasi}

hasil uji menunjukkan bahwa nilai Adjusted $\mathrm{R}$ Square sebesar 0,583, sehingga variabel keputusan pembelian yang dapat di jelaskan oleh word of mouth, healthy lifestyle dan Brand 
Image dalam penelitian ini sebesar 58,3\% sedangankan sebesar $41,7 \%$ dipengaruhi oleh variabel yang tidak dijelaskan dalam penelitian ini.

\section{Pembahasan}

Dari hasil analisis yang dapat di ambil pembahasan yang terkait dengan variabel variabel yang mempengaruhi keputusan pembelian sepeda merek Polygon pada masyarakat Kabupaten Kebumen.

Variabel word of mouth berpengaruh signifikan terhadap keputusan pembelian. Hasil perhitungan uji $\mathrm{t}$ menunjukan nilai koefisien unstandardized beta coeffiecient adalah 0,527 dengan nilai $t_{\text {hitung }}$ sebesar 5,212 dantingkat signifikasi sebesar 0,000, sedangkan $t_{\text {tabel }}$ dalam penelitian ini adalah 1,985. Hasil penelitian ini membuktikan bahwa masyakarat Kabupaten Kebumen yang melakukan pembelian terhadap sepeda merek Polygon dikarenakan kebutuhan mereka dalam berolahraga. Semakin tinggi rasa ingin keniatan untuk berolahraga bersepeda dan mindset yang baik terhadap sepeda merek Polygon maka akan meningkatkan keputusan pembelian.

Variabel healthy lifestyle berpengaruh signifikan terhadap keputusan pembelian. Hasil perhitungan uji $\mathrm{t}$ menunjukan nilai koefisien unstandardized beta coeffiecient adalah 0,631 dengan nilai $t_{\text {hitung }}$ sebesar 6,176 dan tingkat signifikasi sebesar 0,000, sedangkan $t_{\text {tabel }}$ dalam penelitian ini adalah 1,985. Hasil penelitian ini membuktikan bahwa masyakarat Kabupaten Kebumen dengan kebutuhan mereka dalam berolahraga, semakin tinggi rasa ingin untuk berolahraga bersepeda demi untuk terus menjaga kesehatan mereka di masa pandemi dan tanpa adanya kerumunan semakin tinggi maka semakin tinggi untuk memutuskan pembelian terhadap sepeda merek Polygon.

Variabel Brand Image berpengaruh signifikan terhadap keputusan pembelian. Hasil perhitungan uji $\mathrm{t}$ menunjukan nilai koefisien unstandardized beta coeffiecient adalah 0,137 dengan nilai $t_{\text {hitung }}$ sebesar 1,231 dan tingkat signifikasi sebesar 0,221, sedangkan $t_{\text {tabel }}$ dalam penelitian ini adalah 1,985. Hasil penelitian ini membuktikan bahwa tidak adanya pengaruh yang signifikan dari variabel Brand Image karena adanya korelasi yang tinggi antar variabel dependen. Itu di buktikan bahwa Brand Image sepeda merek Polygon di Kabupaten Kebumen sudah sangat baik dan maindset yang tinggi lalu masyarakat sudah mempunyai rasa percaya terhadap sepeda merek Polygon karena merek sudah sangat terkenal maka Brand Image tidak berpengaruh signifikan pada keputuusan pembelian sepeda merek Polygon pada masyarakat Kabupaten Kebumen.

Hasil uji f pada penelitian ini diperoleh sebesar 47,170 dengan tingkat signifikasi 0,000<0,05 yang artinya variabel word of mouth, healthy lifestyle dan Brand Image secara bersama-sama berpengaruh signifikan terhadap keputusan pembelian sepeda merek Polygon di Kabupaten Kebumen.

Dari hasil uji $\mathrm{R}^{2}$ menunjukkan bahwa nilai sebesar 0,583 sehingga dapat disimpulkan bahwa variabel keputusan pembelian yang dapat di jelaskan oleh word of mouth, healthy lifestyle dan Brand Image dalam penelitian ini sebesar 58,3\% sedangankan sebesar 41,7\% dipengaruhi oleh variabel yang tidak dijelaskan dalam penelitian ini. Hal ini mrmbuktikan bahwa variabel keputusan pembelian belum sepenuhnya dijelaskan oleh variabel word of mouth, healthy lifestyle dan Brand Image karena nilainya masih dibawah 100\%. Pada penelitian ini terdapat variabel lain yang menjadi pertimbangan masyarakat Kabupaten Kebumen untuk melakukan pembelian terhadap sepeda merek Polygon. 


\section{Penutup dan Saran}

\section{Simpulan}

Word of mouth berpengaruh yang positif dan signifikan terhadap keputusan pembelian. Hasil perhitungan uji $\mathrm{t}$ menunjukan nilai koefisien unstandardized beta coeffiecient adalah 0,527

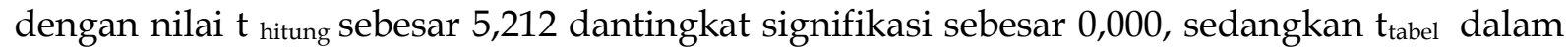
penelitian ini adalah 1,985 berati pengaruh word of mouth terhadap keputusan pembelian adalah signifikan.

Healthy lifestyle berpengaruh positif dan signifikan terhadap keputusan pembelian. Hasil perhitungan uji $\mathrm{t}$ menunjukan nilai koefisien unstandardized beta coeffiecient adalah 0,631 dengan nilai $t_{\text {hitung }}$ sebesar 6,176 dan tingkat signifikasi sebesar 0,000, sedangkan $t_{\text {tabel }}$ dalam penelitian ini adalah 1,985 berati pengaruh healthy lifestyle terhadap keputusan pembelian adalah signifikan.

Brand Image tidak berpengaruh signifikan terhadap keputusan pembelian. Hasil perhitungan uji $\mathrm{t}$ menunjukan nilai koefisien unstandardized beta coeffiecient adalah 0,137 dengan nilai $\mathrm{t}$ hitung sebesar 1,231 dan tingkat signifikasi sebesar 0,221, sedangkan $t_{\text {tabel }}$ dalam penelitian ini adalah 1,985 berati pengaruh Brand Image terhadap keputusan pembelian adalah tidak signifikan.

Word of mouth, healthy lifestyle dan Brand Image secara bersama - sama berpengaruh signifikan terhadap keputusan pembelian. Hal ini didukung oleh hasil uji $\mathrm{R}^{2}$ menunjukkan bahwa nilai sebesar 0,583 sehingga dapat disimpulkan bahwa variabel keputusan pembelian yang dapat di jelaskan oleh word of mouth, healthy lifestyle dan Brand Image.

Sementara hasil uji f pada penelitian ini diperoleh sebesar 47,170 dengan tingkat signifikasi 0,000 < 0,05 yang artinya variabel word of mouth, healthy lifestyle dan Brand Image secara bersama-sama berpengaruh positif dan signifikan terhadap keputusan pembelian sepeda merek Polygon di Kabupaten Kebumen.

Healthy lifestyle mempunyai pengaruh dominan terhadap keputusan pembelian. Hal ini didukung oleh koefisien regresi healthy lifestyle $(0,631)$ paling besar dibandingkan dengan koefisien regresi word of mouth $(0,527)$ dan koefisien regresi Brand Image $(0,137)$.

\section{Referensi}

Aprianto, R. (2016). Pengaruh Brand Image Dan Word Of Mouth Communication Terhadap Keputusan Pembelian Kompor Gas Rinnai Pada Konsumen Kelurahan Cereme Taba Kota Lubuk Linggau. Skripsi. Sekolah Tinggi Ilmu Ekonomi Musi Rawas.

Arikunto, S. (2002). Metodologi Penelitian. Jakarta: Pt. Rineka Cipta.

Asih, F. (2018). Pengaruh Variasi Produk, Iklan Tv Dan Healthy Lifestyle Terhadap Keputusan Pembelian Konsumen Pada Minuman Studi Pada Konsumen Buavita Di Kabupaten Kebumen Sari Buah Merek “Buavita”. Skripsi. STIE Putra Bangsa Kebumen.

Babin, B. J. 2005. Modelling Consumer Satisfaction and word of mouth: Restaurant Patronage in Korea. The Journal of Service Marketing, 19(3). 133-139. 
Elisa, L. (2016). Pengaruh Gaya Hidup Sehat, Citra Merek , dan Iklan Terhadap Keputusan Pembelian Minuman Isotonik Pocari Sweat (Studi pada Masyarakat Kecamatan Buayan). Skripsi. STIE Putra Bangsa Kebumen.

Fitriana. (2011). Analisis Pengaruh Promosi Word of Mouth Terhadap Brand Image Dan Proses Keputusan Kunjungan Kebun Raya Bogor. Skripsi. IPB.

Ghozali, I. (2005). Aplikasi Analisis Multivariate dengan Spss. Semarang: Badan Penerbit Undip. Hasan, A. (2010). Marketing Dari Mulut Ke Mulu. Yogyakarta.

Istantia, S., Kumadji, S., \& Hidayat, K. (2016). Pengaruh Green Marketing Terhadap Citra Merek Dan Keputusan Pembelian (Survei pada Pengguna Produk Ramah Lingkungan Lampu Philips LED di Perum Kepanjen Permai 1, RW 4, Desa Talangagung, Kec. Kepanjen, Malang, Jawa Timur). Jurnal Administrasi Bisnis, 32(1), 174-182.

Kotler, P, \& Armstrong, G. (2008). Prinsip-Prinsip Pemasaran. Edisi Kedua Belas. Jakarta: Penerbit Erlangga.

Kotler, P., \& Keller, K. L. (2012). Marketing Management, 14th, Person Education.

Kotler, P., \& Keller, K. L. (2014). Buku Prinsip Prinsip Pemasaran by Philip Kotler Gary Armstrong. Edisi 12 Jilid I \& 2. Edisi Ke 13. Jakarta: Erlangga.

Mowen, J. C., \& Minor, M. (2001). Akuntansi Manajemen. Jilid 1 Edisi Kelima. Jakarta: Penerbit Erlangga

Oktavianingsih, I., \& Setyawati, H. A. (2020). Pengaruh Kelompok Acuan, Gaya Hidup dan Citra Merek terhadap Keputusan Pembelian Helm Merek INK. Jurnal Ilmiah Mahasiswa Manajemen, Bisnis Dan Akuntansi (JIMMBA), 2(4), 619-630.

Schiffman, L. G., \& Kanuk, L.L. (2010). Consumer Behaviour (10th Ed). New Jersey, Pearson Prentice Hall.

Sernovitz, A. (2012). Word of Mouth Marketing: How Smart Companies Get People Talking, New York: Kaplan Inc.

Setiadi, N. J. (2010). Perilaku Konsumen. Cetakan 4. Edisi Revisi. Jakarta: Kencana.

Solomon, M. R. (2007). Consumer Behaviour: Buying, Having, And Being, Six Edition. New Jersey: Pearson Prentice Hall.

Srikandi. (2013). Faktor Yang Membentuk Komunikasi Word Of Mouth Dan Pengaruhnya Terhadap Keputusan Pembelian Studi Pada Konsumen Ketan Legenda. Skripsi. Universitas Brawijaya Malang.

Sudaryono. (2016). Manajemen Pemasaran Teori dan Implementasi. Yogyakarta: Andi.

Sugiyono. (2009). Metode Penelitian Pendidikan Pendekatan Kuantitatif, Kualitatif, dan RED. Bandung: Alfabeta.

Sugiyono. (2010). Metode Penelitian Pendidikan Pendekatan Kuantitatif, Kualitatif, dan RED. Bandung: Alfabeta.

Suryani, T. (2008). Perilaku Konsumen. Yogyakarta: Graha Ilmu. 
Jurnal Ilmiah Mahasiswa Manajemen, Bisnis dan Akuntansi 3(3) Juni 2021

Sutisna. (2010). Perilaku Konsumen Dan Komunikasi Pemasaran. Bandung: Pt Remaja Rosdakarya.

Sutisna. (2012). Perilaku Konsumen Dan Komunikasi Pemasaran. Edisi Kedua. Bandung: Remaja Rosdakarya.

Tjiptono, F. (2011). Strategi Pemasaran edisi 2, cetakan kelima. Yogyakarta: Andi.

Yosevina, C. (2008). Word of Mouth Bukan Sekedar Ngerumpi. Jurnal PMPM, 11(4), 5-13. 